\title{
Approaching Disability and Educational Inclusion from the "Trinity" Model Perspective
}

\author{
A K Tugli \\ Department of Public Health, School of Health Sciences, University of Venda, Thohoyandou, South Africa. \\ tugli.augustine@univen.ac.za
}

E K Klu

Department of English, School of Human \&Social Sciences, University of Venda, Thohoyandou, South Africa. asongkwesi@gmail.com

\section{Doi:10.5901/mjss.2014.v5n20p2954}

\section{Abstract}

Disability and inclusion should not be mutually exclusive events; rather they must be indivisible entity viewed from the stance of relevant conceptual frameworks and social justice point. Because of individual differences, needs and diversity, educational inclusion of people with disabilities has become a thorny issue and has raised debates from many quarters on how to ensure that educational accommodation is accomplished for all. Inasmuch as disability is a complex phenomenon that underpins the options available to students with disabilities, inclusion has equally been complex due to many associated and interwoven dynamics that come to the fore. Against this background, this paper examines the issue of disability and educational inclusion from a collectivity of three model fused into one model. Based on the assumption that any form of educational inclusion requires a multi-dimensional approach, the paper discusses Social Model of Disability, Inclusive Education Model and the Huitt's Transactional Model of Teaching and Learning as one compact framework referred to as the "Trinity" model. In addition, it critically analyses the dynamics inherent in the model as they impact on the functioning of students with disabilities in the educational environment.

Keywords: disability, dynamics, trinity model, educational inclusion

\section{Introduction and Background}

The strongest argument for inclusion is premised on the principle of social justice where persons with disabilities are expected to enjoy the full range of their human rights and participate in relevant programmes (United Nations High Commission for Refugees (UNHCR), 2011). Disability is part of human diversity that has issues cutting across health, educational, physical, cognitive, affective, social and psychological spectrum of special needs. In a study to investigate the extent of social exclusion for people with disabilities, Gannon and Nolan (2006) noted that people with disabilities experience challenges which stretch from the workplace into labour market programmes, the education system and wider society. From the human rights point of view, disability takes into account the social conditions which disable a group of individuals by ignoring their needs of accessing opportunities in a manner different from others (Distance Education Programme - Sarva Shiksha Abhiyan, 2008). In other words, it is the social constructs that infringe upon the inclusion of people with disabilities in society.

The United Nations Educational, Scientific and Cultural Organization (UNESCO, 2001) defines inclusion as a dynamic process of participation of people within a net of relationships, that is, by legitimizing peoples' interaction within social groups. This notion is founded on the broader social justice philosophy. Inclusion is not only an exposure to diversity but provides opportunities for the development of appropriate attitude towards people with disabilities and the realities of acknowledging individual differences including their strengths and weaknesses in society.

In like manner, Konza (2008) explains that educational inclusion seeks to completely remove the distinction between special and regular education, and to provide an appropriate education for all students, despite their level of disability. This source further argues that it involves a complete restructuring of the educational system so that all schools would have the responsibility of providing the facilities, resources, and an appropriate curriculum for all students irrespective of disability. Konza (2008) cites Bandy and Boyer (1994), Carroll et al, (2003) and Westwood and Graham (2003) as saying research has long established that changing attitudes towards people with disabilities requires, both, information about these disabilities and experience with people with disabilities. This implies that people's perception 
about disability can greatly change positively through inclusion.

Since time immemorial, societies have been viewing the phenomenon of disability from different perspectives. As a result, several models emerged to explain it. Amongst them are the Religious, Charity and Medical Models. According to the Best Resources for Achievement and Intervention Neurodiversity in Higher Education (BRIANHE 2006), these models have had a powerful influence on setting the parameters on how people with impairments are perceived by society. Models of disability are therefore, a useful framework that guides the understanding of disability issues. Against this background, this paper examines the dynamics of the "Trinity" model in relation to disability and educational inclusion.

\section{The "Trinity" Model}

In a survey to investigate the challenges and needs of students with disabilities in an institution of higher education, Tugli (2013) approached his study from three conceptual frameworks which can be referred to as the "Trinity" model (Figure 1).

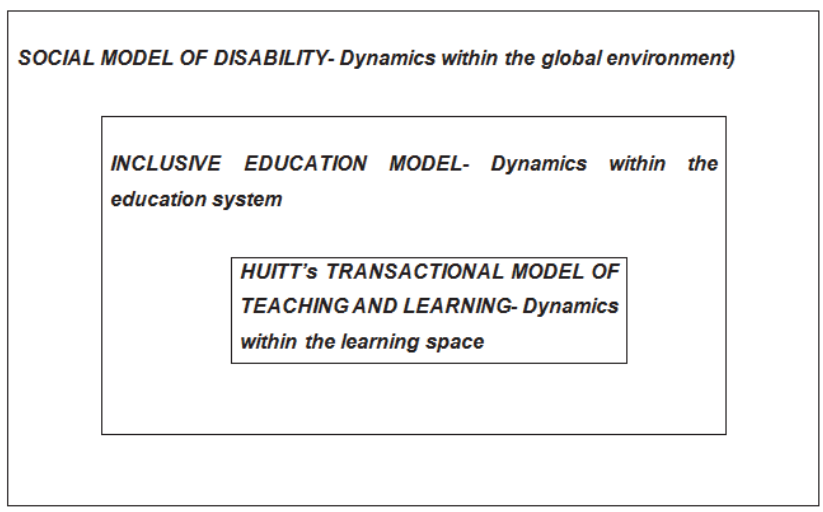

Figure 1: The "Trinity model" (Source: adapted from Tugli, 2013:56)

In the figure, the "Trinity" model is a combination of the Social Model of Disability, the Inclusive Education Model and the Huitt's Transactional Model of Teaching and Learning. Tugli (2013) argues that disability and educational inclusion should be viewed and examined from the "three-in-one" perspective which, therefore, collapses the Huitt' transactional model and Inclusive Education model as subsets of the superset (Social Model).

\subsection{Assumption of the model}

The assumption underlying the "Trinity" model is that any form of educational inclusion requires a multi-dimensional approach, which in this case involves "three-in-one" model paradigm. The complexity in the learning environment warrants a combination of the three models which make the understanding of educational inclusion exhaustive and holistic.

\subsection{Rational of the model}

To date, the authors of this paper have not as yet come across a combination of models that put educational inclusion and disability in one context. By so examining inclusion and disability from one collective perspective depicts that the models are intertwined and indivisible from an educational point of view. This implies that the "Trinity" model approach to inclusive education makes inclusive issues to be addressed from broader and more holistic perspective because anything that affects teaching and learning, or educational system or a universal design will surely disturb the equilibrium of the trinity entity. The significance of this model cannot be over emphasized bearing in mind that barriers to educational inclusion can arise from within the various interlocking parts of the curriculum, the language and medium of learning and teaching, the management and organization of classrooms, equipment and supplies, infrastructure etc (Department of Education (DoE), 2001; Nkoane, 2006). 


\subsection{Discussion of the dynamics of the "Trinity" model}

\subsubsection{The Social Model of Disability- dynamics within the global environment}

Of late the Social Model has become the gold standard of viewing disability. It is a conceptual framework (Samaha, 2007) among many advocates and academics who perceive "disability" as disadvantage caused by the confluence a person's physical or mental traits plus the surrounding environment. All this can be attributed to the way society is organized or at least partly constructed by others (Samaha, 2007). According to Paley (2002) the Social Model of disability identifies systemic barriers, negative attitudes and exclusion by society (purposely or inadvertently). By implication, the society is the main contributory factor in disabling people.

The World Health Organisation (WHO, 2011), argues that dynamics within the global environment have a huge impact on the experience and extent of disability in terms of the choices people with disability will have to make or in terms of accessibility, participation and accommodation. Indeed, environmental factors including natural and un-natural phenomenon influence human life, standard of living, climate, accessible design of the built environment and transport, rehabilitation, support services, employment opportunities etc.

In the world today, it is imperative to acknowledge the presence of special needs people whose needs should inform "universal designs". According to the Burgstahler (2013), "universal design" means the design of products and environment to be usable by all people, to the greatest extent possible, without the need for adaptation or specialized design. Among the increasing numbers of students pursuing education across the globe, are students who fall in various disability groups such as visual impairments, hearing impairments, mobility impairments, health and psychiatric impairments as well as learning disabilities. In the light of this, designing any product or services, cognizance must be taken of the needs of people with disabilities. To this end, the American Speech-Language-Hearing Association (ASHA,2000) argues that special considerations must also be given to factors such as engineering options, safety concerns and costs so that new technologies and software options are available to foster access to education and full academic inclusion of all students.

The Social Model, therefore, alludes that "disability" is the product of the physical, organisational and attitudinal barriers present within society which lead to exclusion of people with disabilities. For this reason, a group of architects, product designers, engineers, and environmental design researchers at North Carolina State University established seven principles of universal design to provide guidance of products and environments. Burgstahler (2013:2-3) spells out the principles as:

$\checkmark$ Equitable use i.e. the design is useful and marketable to people with diverse abilities.

$\checkmark$ Flexibility in use i.e. the design accommodates a wide range of individual preferences and abilities

$\checkmark$ Simple and intuitive i.e. the use of the design is easy to understand, regardless of the user's experience, knowledge, language skills, or current concentration level.

$\checkmark$ Perceptible information i.e. the design communicates necessary information effectively to the user, regardless of the ambient conditions or the user's sensory abilities.

$\checkmark$ Tolerance for error i.e. the design minimizes hazards and the adverse consequences of accidental or unintended actions.

$\checkmark$ Low physical effort i.e. the design can be used efficiently and comfortably, and with minimal fatigue.

$\checkmark$ Size and space for approach and use i.e. appropriate space is provided for approach, reach, manipulation, and use regardless of the user's body size, posture, or mobility.

Though all these principles can conveniently be applied to the design and production of educational products and learning environments for students with disabilities, the capitalistic tendency of profit making can be an inhibiting factor in production of goods and services to accommodate the needs of people with disabilities. At the very best, the Social Model promotes social justice philosophy and normative commitments; however, on its flipside, the model lacks standard control mechanism to enforce compliance to its ideals and to eliminate profiteering.

\subsubsection{The Inclusive Education Model- Systemic dynamics}

Schneider (2009) intimates that it is important to note that inclusion contains a very radical idea of acknowledging diversity which is not found in the idea of integration or mainstreaming of students with disabilities. As a subset of the Social Model of Disability which focuses broadly on disability and macro-economic, political and social structure of society, Inclusive Education Model narrows its focus on the student and the education system. Distance Education 
Programme - Sarva Shiksha Abhiyan (2008) defines the Inclusive Education Model as an educational model that views the education system as a problem to the student with disabilities. In other words, it is the system (with all its dynamics) which should be adapted, modified and made flexible enough to accommodate the diverse needs of all students including those with disabilities (Distance Education Programme - Sarva Shiksha Abhiyan 2008; Schneider 2009).

The structure of the Inclusive Education Model is presented in Figure 2 below:

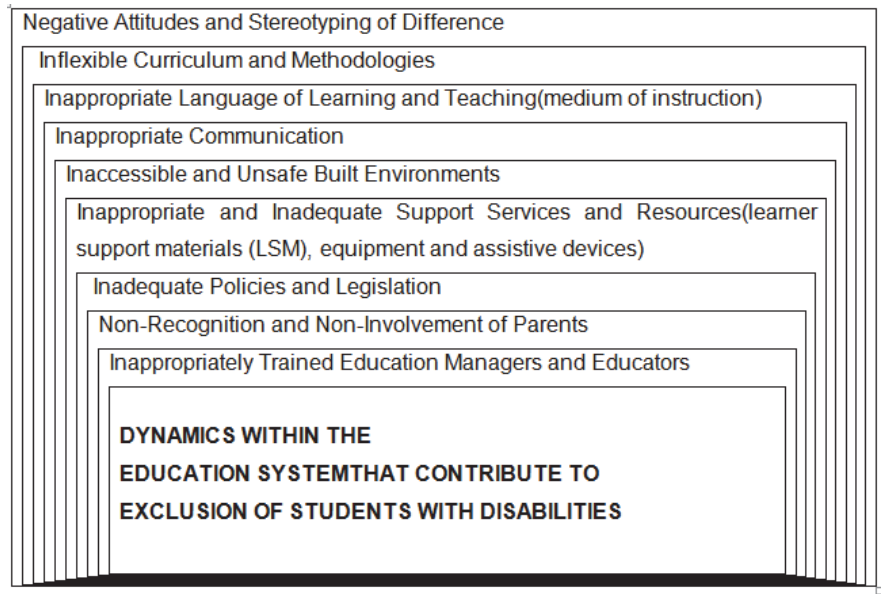

Figure 2: Inclusive Education Model in South Africa (Adapted from: DoE 2001:19; DoE 2005:7-8)

In the model, the dynamics within the education system are explained below with their implications to the student with disabilities:

$\checkmark \quad$ Negative attitudes and stereotyping of difference: this element can affect the social integration of students with disabilities especially the emotionally sensitive and unstable learners. It can lead to withdrawal, depression, suicidal attempts etc.

$\checkmark \quad$ An inflexible curriculum and methodologies: this element can lead to exclusion, high failure and attrition rates.

$\checkmark$ Inappropriate language of learning and teaching: this can lead to learning difficulties and exclusion especially for hearing impaired students who may need sign language.

$\checkmark$ Inappropriate communication: breakdown in communication between students with peers and other stakeholders will likely result in isolation and feeling of not being recognised as part of the social community.

$\checkmark$ Inaccessible and unsafe built environments: this can pose a lot of challenge to the visually and physically impaired students. It will deny them access to essential facilities and services.

$\checkmark \quad$ Inappropriate and inadequate support services and resources: this can lead to denial of the right to be provided with essential learning support materials, assistive devices and psychosocial care and support.

$\checkmark$ Inadequate policies and legislation: this can lead to lack of inclusion provision made for students with disabilities in the institutional culture and practices. E.g. lack of policy in the admission of students with disabilities may deny them with essential concessions that must be made for them during admission.

$\checkmark$ Non-recognition and non-involvement of parents: parents are important stakeholders in education. Being given recognition will help give moral, social and family support to students with disabilities and the institutions.

$\checkmark$ Inadequately and inappropriately trained education managers and educators: the main drivers of teaching and learning are educators and support staffs; without adequately trained educators and managers professional functions expected of educators and managers will be unattainable. As a result students with disabilities will not achieve the educational outcomes and expectations.

In a nutshell, Inclusive Education Model is based on the assumption that the education system is a challenge to the child that needs special support. As a conceptual framework within the "Trinity" model, Inclusive Education Model seeks to ensure that the necessary support system is provided to enhance the learning potentials of all students irrespective of their disability status (DoE, 2005). 


\subsubsection{The Huitt's Transactional Model of Teaching and Learning- dynamics within the learning space}

An inclusion process can not be complete if reasonable adjustments are not made to ensure that students with disabilities are appropriately accommodated in learning space where teaching and learning take place. In an inclusive education, the mode and fashion of curriculum delivery plays an important role in the learning experience of students with disabilities. Based on the notion that learning is individual but the context is always social, students with disabilities also have individual strengths, weaknesses, expectations and aspirations to share with their non-disabled counterparts in a socially conducive learning space or environment (ASHA, 2000). This is where the Huitt's Transactional Model of Teaching and Learning fits as the innermost subset of the two other models already presented in Figure 1 above.

Whilst the Social and Inclusive Education Models address disability and inclusion in a broader context of social environment and educational system respectively, the Huitt's Transactional Model of Teaching and Learning explores inclusion within the core business context of an educational institution. Figure 3 below depicts the Huitt's Transactional Model which focuses on a range of domains such as inputs, processes, outcomes, and contextual factors that can impact on teaching and learning. These domains are crucial in the learning experiences of students with disabilities and the inclusion of all students irrespective of their learning challenges.

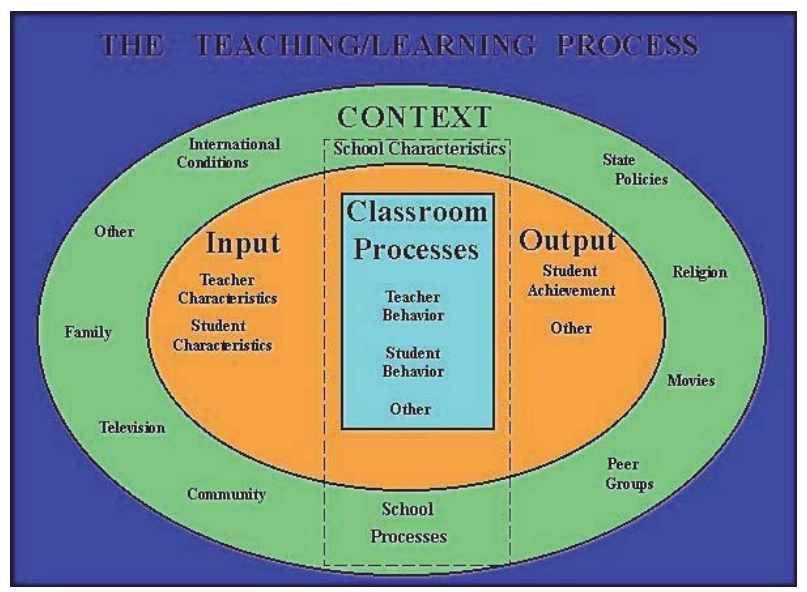

Figure 3: Huitt's Transactional Model of Teaching and Learning (Adopted from Mcllrath \& Huitt 1995:3)

The Huitt's model (Figure 1) attempts to categorise and organise all the variables that might be used to answer the question, "Why do some students learn more than other students" (Mcllrath \& Huitt 1995)? The model classifies the process into four categories. The dynamics within each category are explained below with their implications to the student with disabilities:

$\checkmark$ Context: the context explores factors outside of the classroom that may influence teaching and learning. For students with disabilities family and home backgrounds, community, environments and psycho-social support systems can all impact on their learning. These are influences that are externally exerted but find expression in the learning space.

$\checkmark$ Input: the input process interrogates inherent characteristics such as disability, gender, ethnicity etc. of students and teachers that can impact on teaching and learning.

$\checkmark$ Classroom processes: the classroom processes take into account the teacher and the student interface, relationships, attitudes and behaviours. Students with disabilities need to learn in a climate that is conducive to their learning and sensitive to their needs.

$\checkmark$ Output: the output process is the measure of the end product. This process has to do with student attainment and preparation for independent living and career prospects (Mcllrath \& Huitt 1995). This is where the achievement of the learning outcomes are evaluated and reflected upon. For students with disabilities, achieving the desired outcomes will make them competitive and less dependent. Hence, the output process is also a test of the extent to which students with disability are included and supported to realize the goals.

The model, therefore, takes into cognisance all aspects that play key roles in accomplishing both learning and 
teaching outcomes. It seeks to endorse learner-centered approach where learner needs and circumstances are explored and considered in the teaching and learning process. This gives room for recognizing, accommodating and meeting the learning needs of all students without stereotyping or pigeon-holing of students into specific groups.

\title{
3. Discussion
}

Though promoting the inclusion of people with disabilities has become a universal imperative, viewing it has been done in a piecemeal fashion of using one single framework. In the light of this, the trinity model examined in this paper provides a new thinking on how educational inclusion of people with disabilities should be approached. The compelling motive of adopting the model emanate from the realization of the fact that challenges associated with educational inclusion revolve around factors within the learner, within the centre of learning, within the education system and within the broader social economic and political system (Nkoane, 2006). On the strength of this notion the paper looks at a number of dynamics that are associated with inclusion of students with disabilities firstly into the global environment, secondly into the education system and lastly into the learning environment where the core business of education takes place. This is in line with Tugli's (2013:57) assertion that:

\begin{abstract}
".....while the Social Model of Disability places strong premium on 'Universal Enabling Environment' for people with disabilities, the Inclusive Education Model and Huitt's Transactional Model narrow their premiums down to 'Enabling Educational System' and 'Enabling Classroom Environment' for learners with disabilities in educational institutions respectively."
\end{abstract}

Furthermore the three models portrayed in the above statement are not presented as mutually exclusive neither are they presented as independent entities; but they are examined as complementary and overlapping models that are integrated into one model. In other words, the Social Model of Disability being the main model was complemented by the Inclusive Education Model and the Huitt's Transactional Model of Teaching and Learning. As explained earlier, the latter two models are not independent of each other; but they are mutually linked and embedded in the Social Model (Figure 1).

\section{Conclusion}

Notwithstanding the fact that disability and inclusion have generated and continue to generate robust debates globally, the authors of this paper are not under any illusion to believe that the "Trinity" model is an absolute panacea to disability issues. Instead, the model and its inherent dynamics have widened the perspectives of perceiving educational inclusion vis-à-vis other relevant conceptual frameworks. Above the dynamics discussed in the paper also opens the forum for more vibrant debate on issues such as universal design and social justice for people with disabilities with special focus on opportunities for those students who require special needs to be fully accommodated. However, achieving full inclusion requires a re-visit of our social policies, programmes, services and designs that will take into account alternatives of accommodating individual differences, diversity, needs and aspirations of everyone.

\section{References}

American Speech-Language-Hearing Association (ASHA). 2000. Learning Disabilities: Issues in Higher Education. From: www.asha.org/policy (accessed 8 August 2012)

Bandy, H. E. \& Boyer, W. A. R. (1994). The impact of special needs students in the rural areas of British Colombial: In Konza, D. 2008. Inclusion of students with disabilities in new times: responding to the challenge. From: http://ro.uow.edu.au/learning/ (accessed 6 June 2013).

Best Resources for Achievement and Intervention Neurodiversity in Higher Education (BRIANHE). 2006. The social model of disability. From: info@brainhe.com (accessed 02 October 2011).

Burgstahler, S. 2013. Universal Design. University of Washington: DO-IT publication.

Carroll, A., Forlin, C., \& Jobling, A. 2003.The impact of teacher training in special education on the attitudes of Australian preservice general educators towards people with disabilities. Teacher EducationQuarterly, 30(3), pp 65-73.

Department of Education (DoE). 2001. White paper 6 on special needs education and building an inclusive education and training system. Pretoria: Government Printer.

Department of Education (DoE). 2005. Directorate: inclusive education. Conceptual and operational guidelines for the implementation of inclusive education \& special schools as resources centres. Pretoria: Government Printer.

Distance Education Programme - Sarva Shiksha Abhiyan. 2008. In-service teacher education on inclusive education. New Delhi: Distance Education Programme - Sarva Shiksha Abhiyan. 
Gannon, B \& Nolan B. 2006. The dynamics of disability and social inclusion. Dublin: The Equality Authority.

Konza, D. 2008. Inclusion of students with disabilities in new times: responding to the challenge. From:http://ro.uow.edu.au/learning/ (accessed 6 June 2013)

Mcllrath, D \& Huitt, W. 1995.The teaching-learning process: a discussion of models educational psychology interactive. Valdosta: Valdosta State University.

Nkoane, MM. 2006. An analysis of factors inhibiting the access of students with special needs to higher education in the Free State. The Centre for Higher Education Studies and Development, Faculty of the Humanities. Bloemfontein: University of the Free State.

Paley, J. 2002. "The Cartesian melodrama in nursing." Nursing Philosophy 3 (3): 189-192. doi:10.1046/j.1466-769X.2002.00113.x.

Samaha, AM. 2007. What god is the social model of disability? From: http://www.law.uchicago.edu/academics/publiclaw/index.html (Accessed 10 June 2013)

Schneider, C. 2009. Equal is not enough - current issues in inclusive education in the eyes of children. International Journal of Education,1(1), 1- 14.

Tugli, AK. 2013. Challenges and needs of learners with disabilities in an inclusive institution of higher education in the Limpopo province of South Africa. Department of Health Studies. Pretoria: University of South Africa (UNISA).

United Nations High Commission for Refugees (UNHCR) 2011. Working with persons with disabilities in forced displacement. Geneva: United Nations.

United Nations Educational, Scientific and Cultural Organisation (UNESCO). 2001. Inclusive schools and community support programmes. Paris: UNESCO.

Westwood, P. \& Graham, L. (2003). Inclusion of students with special needs: benefits and obstacles perceived by teachers in New South Wales and South Australia. Australian Journal of Learning Disabilities, 8(1), pp 3-15.

World Health Organization (WHO). 2011. World report on disability. Malta: WHO Library Cataloguing-in-Publication Data. 